\title{
Growth Hormone Insensitivity Syndrome
}

National Cancer Institute

\section{Source}

National Cancer Institute. Growth Hormone Insensitivity Syndrome. NCI Thesaurus.

Code C129867.

A group of inherited syndromes in which there is impaired growth hormone signaling, despite normal or increased growth hormone concentrations. The syndromes are characterized by some or all of the following: prenatal and/or postnatal growth failure, immature facial features, microcephaly, neurocog nitive deficiencies, sensorineural hearing loss, immune dysregulation, and delayed puberty. 